\section{ORIGINAL RESEARCH}

J.P. Cruz

M. Chow

C. O'Kelly

B. Marotta

J. Spears

W. Montanera

D. Fiorella

T. Marotta

\title{
Delayed Ipsilateral Parenchymal Hemorrhage Following Flow Diversion for the Treatment of Anterior Circulation Aneurysms
}

\author{
BACKGROUND AND PURPOSE: The PED is a flow-diverting stent designed for the treatment of cerebral \\ aneurysms. We report 4 cases of delayed ipsilateral IPH following the technically successful treatment \\ of anterior circulation aneurysms with the PED.
}

\begin{abstract}
MATERIALS AND METHODS: Clinical and imaging data from all patients undergoing aneurysm treatment with the PED at 2 institutions were analyzed to assess the incidence of delayed IPH after treatment with the PED.
\end{abstract}

\begin{abstract}
RESULTS: A total of 66 patients (47 anterior circulation) with cerebral aneurysms underwent treatment with a PED between January 2008 and November 2010. Four patients experienced delayed periprocedural IPH, all after the treatment of anterior circulation aneurysms $(8.5 \%, 4 / 47)$. The aneurysm size ranged from 5 to $21 \mathrm{~mm}$. All IPHs occurred within the cerebral hemisphere, ipsilateral to the treated aneurysm, and were anatomically remote from the treated aneurysms. All procedures were uncomplicated, and patients emerged from general anesthesia at neurologic baseline. The hemorrhages became clinically evident between 1 and 6 days after the procedure. Two patients had unfavorable outcomes (mRS scores, 4 and 6).
\end{abstract}

CONCLUSIONS: Delayed IPH may occur after the treatment of anterior circulation aneurysms with flow diverters. This complication does not seem to be restricted to a specific aneurysm subtype and does not seem to be related to an intraprocedural complication or solely attributable to DAT.

ABBREVIATIONS: DAT = dual antiplatelet therapy; FD = flow diversion; IPH = intraparenchymal hemorrhage; $I \mathrm{QR}=$ interquartile range; $\mathrm{mRS}=$ modified Rankin Scale; PED = Pipeline Embolization Device

$F^{\prime}$ low diverters have recently received full European Conformity Mark approval for commercialization within the European Union and FDA approval for their use within the United States. To date, the reported periprocedural and midterm follow-up results have been extremely impressive, ${ }^{1-5}$ with very high rates of complete aneurysm occlusion and relatively low rates of postoperative morbidity and mortality. However, as more experience is accrued, their potential limitations and optimal applications are becoming increasingly evident. ${ }^{6-12}$

We report 4 cases of delayed ipsilateral IPH following the treatment of anterior circulation aneurysms with the PED.

\section{Materials and Methods}

\section{Data Collection}

All patients treated with the PED (ev3/Covidian, Irvine, California) between January 2008 and November 2010 at 2 different institutions

Received November 23, 2011; accepted after revision January 25, 2012..

From the Division of Neurosurgery (M.C., C.O.), Department of Surgery, University of Edmonton, Edmonton, Alberta, Canada; Department of Medical Imaging (J.P.C., J.S., W.M., T.M.), University of Toronto, Toronto, Ontario, Canada; Division of Neurosurgery (J.S.), Department of Surgery, University of Toronto, Saint Michael's Hospital, Toronto, Ontario, Canada; Sydney Medical School (B.M.), University of Sydney, Sydney, New South Wales, Australia; and Department of Neurosurgery (D.F.), Cerebrovascular Center, Stony Brook University Medical Center, Stony Brook, New York.

Paper previously presented as a Flash Presentation (3 minutes long, 5 slides) at: Annual Meeting of the World Federation of Interventional and Therapeutic Neuroradiology, Cape Town, South Africa; November 8, 2011.

Please address correspondence to Thomas R. Marotta, MD, FRCP, St. Michael's Hospital, 30 Bond St, Toronto, ON, Canada, M5B1W8; e-mail: marottat@smh.ca

http://dx.doi.org/10.3174/ajnr.A3065

were included. All available clinical and neuroimaging data were reviewed. Specifically, each case was reviewed for the occurrence of postprocedural IPH. The aneurysm size and location, procedural details, clinical presentation at the time of IPH diagnosis, subsequent imaging, and clinical outcome at last follow-up were evaluated.

\section{PED Procedures}

In general, all patients were pretreated with both aspirin $(325 \mathrm{mg})$ and clopidogrel (600-mg loading dose or $75 \mathrm{mg}$ daily for a minimum of 5 days) before treatment. No tests of in vitro platelet function for clopidogrel clinical response and dosing were used. One patient with hemorrhage underwent stent placement on clopidogrel only. Aspirin was introduced gradually with a desensitization protocol during the immediate postprocedural period. All procedures were performed with the patient under general anesthesia. Procedural heparinization was used to achieve a targeted activated clotting time ranging between 250 and 300s. A transfemoral access was used with either a $6 \mathrm{~F}$ guiding catheter or $6 \mathrm{~F}$ long sheath. Following angiographic evaluation of the targeted aneurysms, including rotational angiography, a 0.027-inch microcatheter (Marksman, ev3/Covidian) was manipulated across the targeted landing zone over a standard 0.014-inch microguidewire. Once in position, PEDs were delivered to reconstruct the parent artery defect, with multiple partially overlapping devices used as needed to bridge normal arterial segments or achieve the desired flow effect. Following stent delivery, control angiography was performed in the working angles for treatment as well as in a branch vessel projection.

\section{Statistical Analysis}

Demographic data and aneurysm size are expressed in medians and IQRs, given the small sample size. 

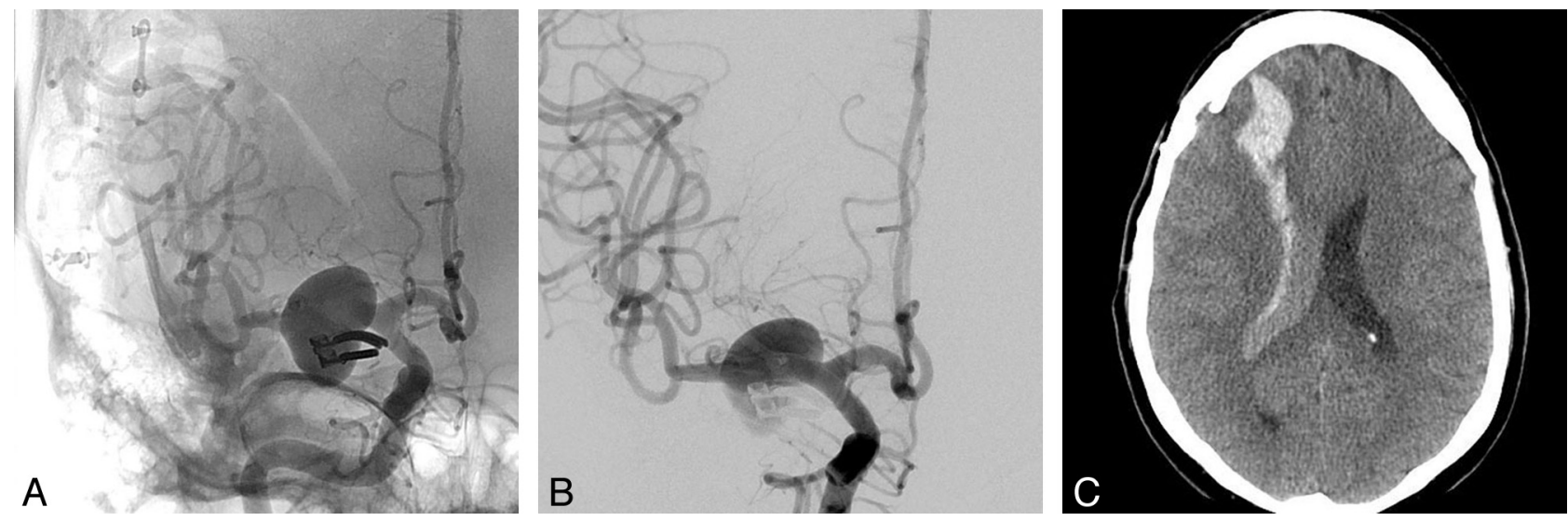

Fig 1. A, Right ICA anteroposterior angiogram showing a previously clipped right M1 segment aneurysm with a large recurrence. $B$, Immediate post-PED deployment appearance. Note the amount of contrast stasis within the aneurysm sac. C, NCCT 1 day after the procedure shows a right frontal lobar hematoma emptying into the ventricle with no significant midline shift. The patient presented with a left hemiplegia, which fully recovered on subsequent follow-up.
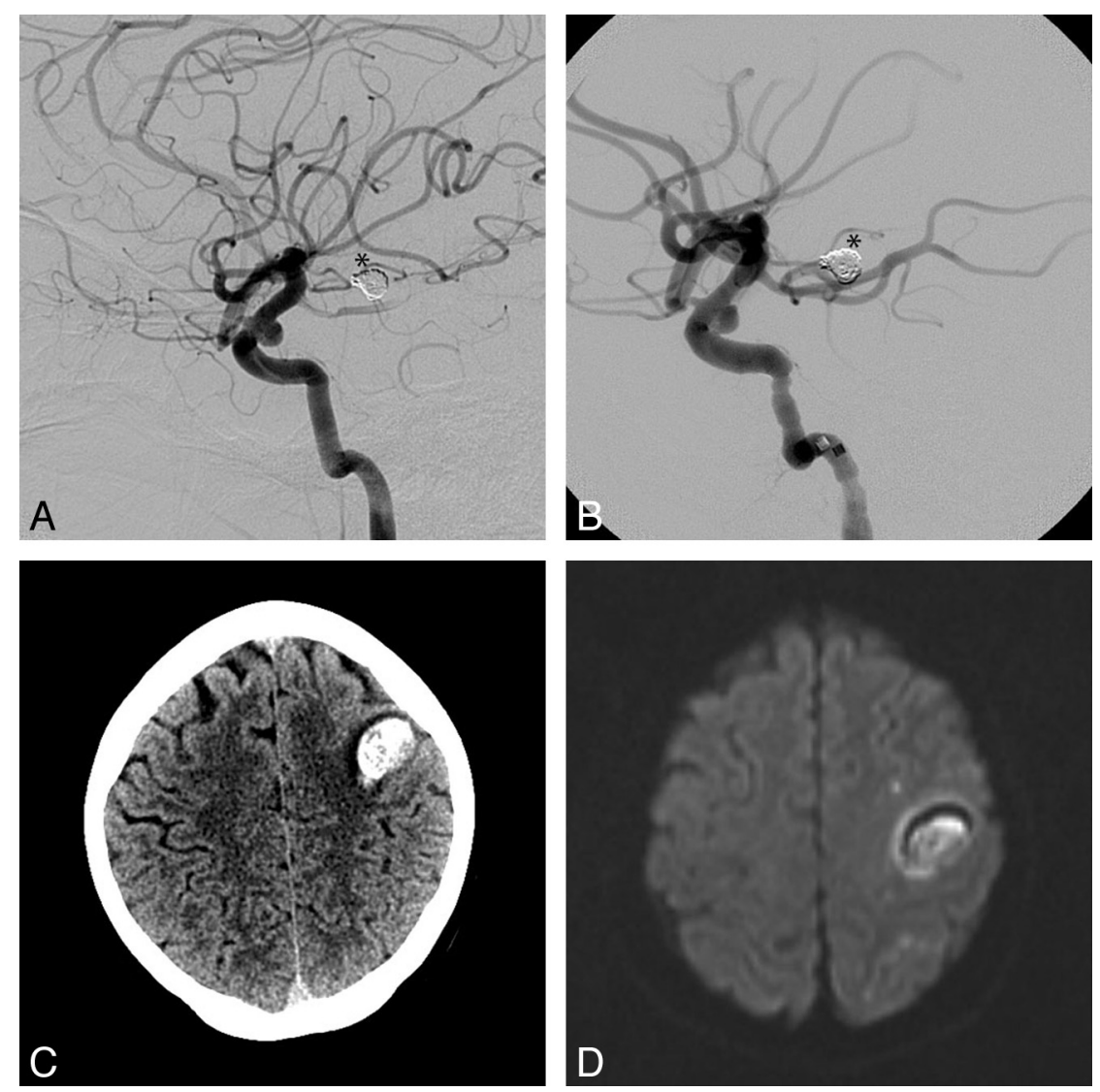

Fig 2. Left ICA lateral angiogram with a small broad neck supraclinoid saccular aneurysm pre- $(A)$ and post-PED deployment $(B)$. Coils from a previously treated basilar tip aneurysm are seen (asterisk). NCCT $(C)$ and DWI MR imaging $(D)$ sequences show a subcortical frontal hematoma and subcortical small ischemic lesions. Note the absence of a large associated cortical ischemic infarct.

\section{Results}

A total of 66 patients (47 anterior circulation) with cerebral aneurysms underwent treatment with the PED between January 2008 and November 2010. Of these, 4 patients experienced delayed periprocedural IPH. These included 3 females and 1 male (median age, 60 years; IQR, 15.75 years). Two patients were heavy smokers; 2 patients had well-controlled hypertension.

\section{Aneurysm Characteristics}

All hemorrhages occurred after the treatment of anterior circulation aneurysms ( 4 of 47 cases; 8.5\%). These aneurysms involved the proximal MCA $(n=1)$ (Fig 1) or supraclinoid segment of the ICA $(n=3)$ (Figs 2-4). Median aneurysm size was $9.5 \mathrm{~mm}$ (IQR, $4.75 \mathrm{~mm}$ ). One of the larger aneurysms demonstrated a fusiform morphology. Three aneurysms were previously treated (1 clipped, 1 coiled, 1 PED) (Table). 

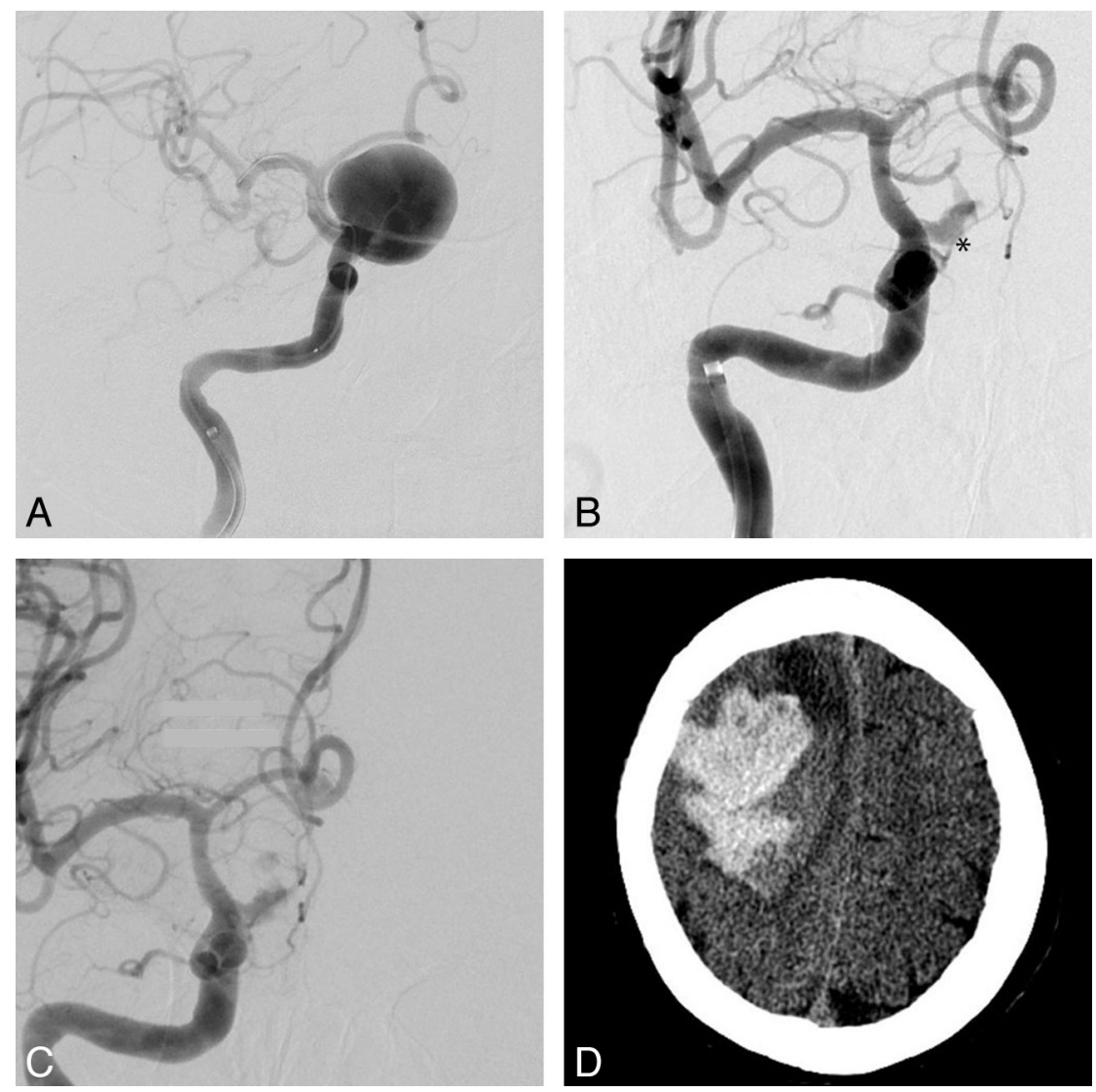

Fig 3. A, Initial right ICA anteroposterior (AP) angiogram with a giant supraclinoid ICA aneurysm before PED deployment (the stent is collapsed within the microcatheter). Right ICA AP angiogram 3 months later, with persistent early aneurysm filling (asterisk) pre- $(B)$ and postdeployment $(C)$ of 2 more PEDs. The aneurysm sac showed significant interval enlargement and development of a daughter bleb (images not shown), so a new PED was placed to increase the flow effect. D, NCCT 1 day later shows a large acute right lobar hematoma with significant mass effect. The patient survived with a persistent left attenuated hemiparesis.

\section{Intraparenchymal Hemorrhage Characteristics and Neuroimaging}

All IPHs occurred within the cerebral hemisphere ipsilateral to the treated aneurysm (3 frontal lobe, 1 temporal lobe). Hemorrhages ranged in largest diameter from 36 to $72 \mathrm{~mm}$ (median, $59 \mathrm{~mm}$; IQR, $24.75 \mathrm{~mm}$ ). All hemorrhages were anatomically remote from the treated aneurysms. A review of the operative reports and procedural imaging by the operators did not reveal any specific intraprocedural details to which the hemorrhages could be attributed. Two of the 4 patients with hemorrhage had MR imaging-DWI either before or after the hemorrhage. In both patients, several small embolic infarcts were distributed within the ipsilateral cerebral hemisphere.

\section{Clinical Course}

All procedures were technically successful and uncomplicated. All patients emerged from general anesthesia at neurologic baseline and remained well during the immediate postoperative period. Blood pressure was closely monitored in an intensive care unit in the early postoperative period. The hemorrhages became clinically evident between 1 and 6 days after the procedure (median, 1.5 days; IQR, 2). Three patients presented with hemiplegia or hemiparesis; 1 patient presented with loss of consciousness. One patient fully recovered, 1 has slight disability, 1 has moderate/severe disability, and 1 patient died.

\section{Discussion}

\section{Delayed Ipsilateral IPH: A Complication Related to the Treatment of Anterior Circulation Aneurysms with Flow Diversion?}

Although the hemorrhages were anatomically remote from the treated aneurysms, several factors support the conclusion that these are related (in some way) to the FD procedure. First, although all procedures were technically successful and the patients emerged from anesthesia neurologically intact, all hemorrhages occurred during the immediate periprocedural ( $<24$ hours) or early postprocedural period (days). Second, all the IPHs occurred in the vascular distribution of the reconstructed vascular segment. If a spontaneous IPH could potentially occur within either the ipsilateral hemisphere, the contralateral hemisphere, or the posterior circulation distribution, the odds of 4 consecutive IPH events occurring by chance within the ipsilateral hemisphere would be $1 / 3$ to the fourth power or $1 / 81(1.2 \%)$. Third, the rate $(8.5 \%)$ at which IPH was observed in our series far exceeded that which would be expected as a sequela of dual antiplatelet therapy alone. ${ }^{13}$ For example, the annual risk of major parenchymal hemorrhage is $1.1 \%-1.8 \%$ in patients with DAT for secondary stroke prevention. ${ }^{14}$

The rate of IPH in this series (8.5\%) is higher than the 2.2\% reported after stent-assisted coiling. ${ }^{15}$ A detailed analysis of a 

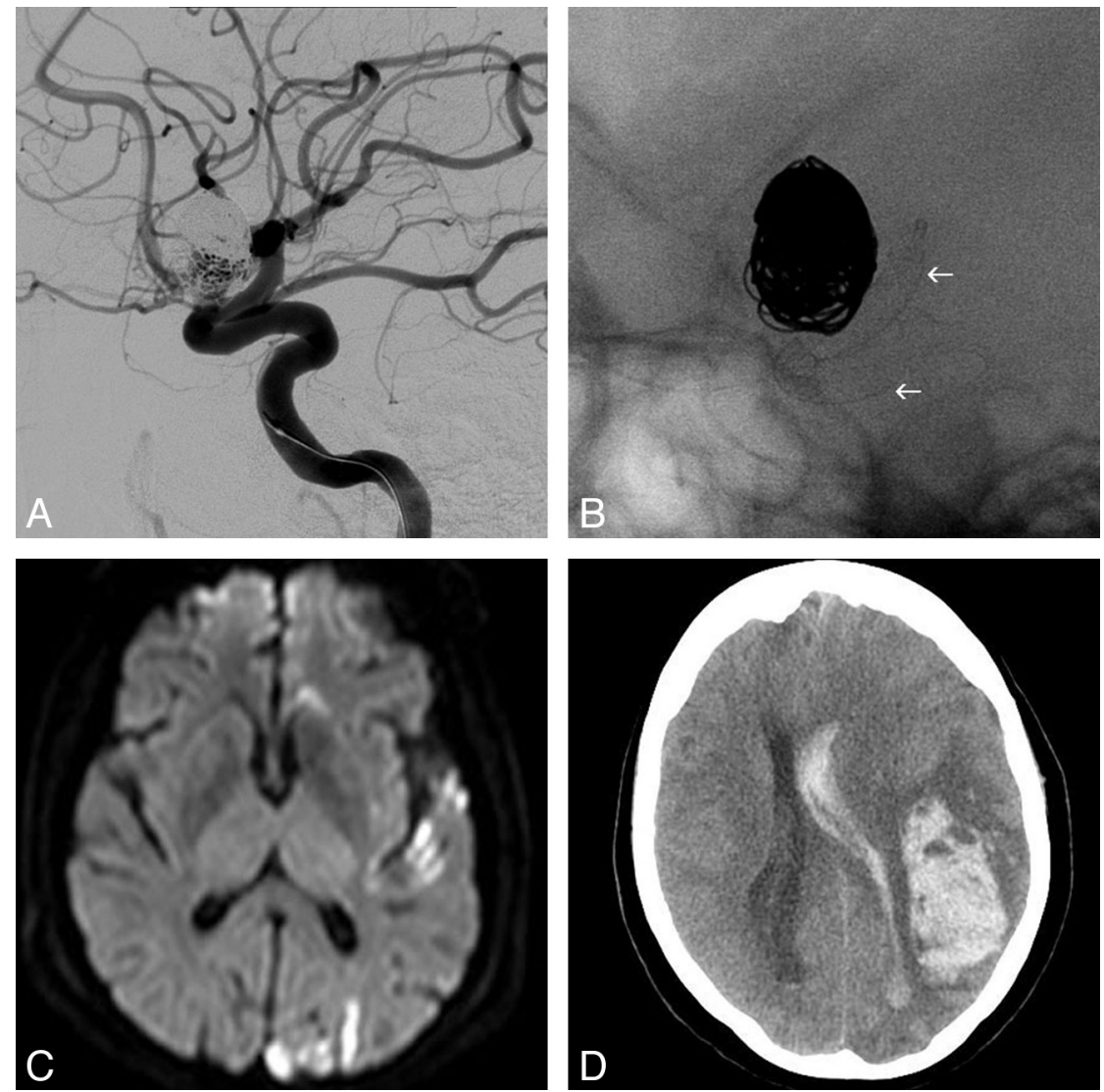

Fig 4. $A$, Left ICA lateral angiogram showing the previously coiled supraclinoid aneurysm with a significant residual filling. $B$, Single-shot lateral image with the PED fully deployed covering the neck of the aneurysm (arrows). C, DWI 48 hours later shows multiple left cortical ischemic lesions. D, NCCT 6 days later shows a large left frontal lobar hematoma, emptying into the ventricle, with marked midline shift and mass effect. The patient died 24 hours later.

\begin{tabular}{|c|c|c|c|c|c|c|c|c|c|c|}
\hline \multicolumn{11}{|c|}{ Patients who presented with ipsilateral IPH after treatment with the PED } \\
\hline No. & $\begin{array}{c}\text { Sex/Age } \\
\text { (yr) }\end{array}$ & Co-Morbidities & Aneurysm Type/Location & $\begin{array}{l}\text { Size }^{\mathrm{a}} \\
\text { (Largest } \\
\text { Diameter, } \\
\mathrm{mm} \text { ) }\end{array}$ & $\begin{array}{l}\text { Previous } \\
\text { Treatment }\end{array}$ & $\begin{array}{l}\text { No. of } \\
\text { PED }\end{array}$ & DAT Regimen & $\begin{array}{l}\text { Time to } \\
\text { Bleed } \\
\text { (days) }\end{array}$ & $\begin{array}{l}\text { Hematoma } \\
\text { Size } \\
(\mathrm{mm})\end{array}$ & $\begin{array}{l}\text { Outcome } \\
\text { (mRS) }\end{array}$ \\
\hline 1 & $\mathrm{M} / 53$ & $\begin{array}{l}\text { Smoker (40 } \\
\text { pack-years) }\end{array}$ & Fusiform/R MCA & 21 & Clipped & 1 & $\begin{array}{l}\text { ASA, } 325 \mathrm{mg} ; \\
\text { clopidogrel, } 75 \mathrm{mg} \\
\text { Started } 5 \text { days before }\end{array}$ & 1 & $49 \times 21$ & 0 \\
\hline 2 & $F / 49$ & $\begin{array}{l}\text { Smoker (68 } \\
\text { pack-years) } \\
\text { Asthma }\end{array}$ & Saccular/L supraclinoid ICA & 5 & None & 1 & $\begin{array}{l}\text { ASA, } 325 \mathrm{mg} ; \\
\text { clopidogrel, } 75 \mathrm{mg} \\
\text { Started } 5 \text { days before }\end{array}$ & 2 & $36 \times 23$ & 2 \\
\hline 3 & $\mathrm{~F} / 67$ & HTN & Saccular/R supraclinoid ICA & 10 & PED (1) & 2 & $\begin{array}{l}\text { Patient on DAT because } \\
\text { of previous PED } \\
\text { ASA, } 325 \mathrm{mg} ; \\
\text { clopidogrel, } 75 \mathrm{mg}\end{array}$ & 1 & $72 \times 61$ & 4 \\
\hline 4 & $\mathrm{~F} / 70$ & HTN & Saccular/R supraclinoid ICA & 9 & Coiled & 1 & $\begin{array}{l}\text { Clopidogrel, } 75 \mathrm{mg} \\
\text { Heparin IV } \\
\text { Progressive aspirin } \\
\quad \text { desensitization }\end{array}$ & 6 & $70 \times 49$ & 6 \\
\hline
\end{tabular}

Note:- L indicates left; R, right; ASA, acetylsalicylic acid; HTN, hypertension.

a Size of the filling portion of the aneurysm as seen on angiography, measured in the single largest diameter.

${ }^{\mathrm{b}}$ Size measured as the largest oblique diameters on axial CT images.

cohort of 284 patients treated with the Neuroform stent (Boston Scientific, Natick, Massachusetts) showed a 1.1\% (3/284) rate of spontaneous IPH $>48$ hours after treatment. ${ }^{16}$ Most interesting, the 3 delayed hemorrhages observed were equally distributed relative to the reconstructed vascular segment: 1 ipsilateral, 1 contralateral, and 1 within the posterior circulation after treatment of an anterior circulation aneurysm. These data would suggest that ipsilateral postprocedural IPH might be a phenomenon that is somehow uniquely associated with flow-diverting devices. 


\section{Delayed Ipsilateral IPH Does Not Appear to Be Related to the Size or Morphology of the Treated Lesion}

The aneurysms that went on to postprocedural hemorrhage ranged widely in size, configuration, and previous treatments (Table), unlike the process of mural destabilization and delayed rupture, which appears to be almost exclusive of very large and giant aneurysms. ${ }^{8,10,17}$ As such, this complication, if consistently observed, may limit the use of the PED in aneurysms amenable for other treatment modalities with a lower overall morbidity and mortality. ${ }^{18-22}$

\section{Putative Etiology of Delayed Ipsilateral Parenchymal Hemorrhage after Flow Diversion}

Due to the early stage of the clinical application of the FD technique and the uncharacterized but apparently low incidence of this phenomenon, the available data on which to base a mechanistic hypothesis are scant.

An initial consideration was that these hemorrhages were related to intraprocedural microwire perforations; however, this explanation was discarded for several reasons. First, the hemorrhages, though ipsilateral, were primarily lobar, distal to the aneurysms, and not consistently in a distribution that would be concordant with the intraprocedural location of the microwire. Second, all occurred at least 1 day after the index procedure, which would not be compatible with procedural vascular perforation that typically becomes clinically obvious within the first few hours.

Another consideration would be hemorrhagic transformation of clinically silent small periprocedural embolic infarcts seen in the 2 patients who had postprocedure MR imaging, as proposed by Fischer et al. ${ }^{23} \mathrm{~A}$ number of studies have quantified the incidence of small clinically silent periprocedural DWI lesions after endovascular procedures, demonstrating that such lesions are not uncommon, ${ }^{24-27}$ but so far, to our knowledge, no reports documenting the postprocedural hemorrhagic transformation of these types of lesions exist, even in the setting of DAT.

Our proposed hypothesis is that the reconstruction of the flexible arteries of the carotid siphon with the PED could reduce the local compliance of that vascular segment, altering the "Windkessel effect," changing the blood pressure waveform transmitted to the distal cerebrovasculature ${ }^{28,29}$ - that is, if segmental vascular reconstruction with the PED reduces arterial compliance, the blood pressure waveform transmitted beyond the reconstructed segment might exhibit a higher systolic peak and a lower diastolic trough (ie, a larger pulse pressure), and this alteration could contribute to delayed postprocedural ipsilateral IPH. ${ }^{30}$ The standard method to measure vessel wall compliance is the echo-tracking system, ${ }^{31}$ but no devices exist for intracranial vessels. Devices to measure in vivo vessel wall compliance with optical coherence elastography are under development, ${ }^{32}$ as well as noninvasive imagebased computer models. ${ }^{33}$ These may allow measuring the changes in the vessel wall elasticity and comparing these changes among the different intracranial stents.

We acknowledge several limitations of our series. The sample size is small, with a heterogeneous group of aneurysm types, which precludes any statistical analysis for potential risk factors; but at the same time, this case series shows that this phenomenon is not exclusive to a specific subtype of lesion.
Also, no in vitro platelet function test was used to measure the level of platelet antiaggregation, but the clinical utility in determining clopidogrel clinical response and dosing of commercially available tests is still controversial. ${ }^{34,35}$ Also, the conducted trials in the cardiology literature are designed to measure reduction in thromboembolic events. ${ }^{36}$ To our knowledge, no reports on "over-antiplatelet inhibition" and increased hemorrhagic complications have been reported in the endovascular literature.

\section{Conclusions}

Delayed ipsilateral IPH may occur after the treatment of anterior circulation aneurysms with flow diverters. This phenomenon appears independent of aneurysm size, morphology, or anatomic complexity and does not seem to be directly related to an intraprocedural event (eg, a distal wire perforation). As such, no factors have been identified that might allow operators to prospectively identify patients who might be at risk for this complication.

Disclosures: Cian James O'Kelly—UNRELATED: Other. proctor fee, Comments: reimbursement for providing proctoring assistance with PED cases. David Fiorella-RELATED: Consulting Fee or Honorarium: ev3, Covidien, Comments: Pipeline proctoring (reimbursed for travel expenses only), ev3 paid consultant $(\$ 10,000)$, Fees for Participation in Review Activities (such as data monitoring boards, statistical analysis, end point committees, and the like). ev3, Covidien, Comments: Pipeline proctoring, UNRELATED: Consultancy. Codman Neurovascular, NFocus, WL Gore, Grants/Grants Pending. National Institutes of Health (Stenting and Aggressive Medical Management for Preventing Recurrent Stroke in Intracranial Stenosis), ${ }^{*}$ MicroVention/Terumo, ${ }^{*}$ Siemens, ${ }^{*}$ Payment for Lectures (including service on Speakers Bureaus). Codman Neurovascular, Micrus, MicroVention, ev3, Comments: Micrus-Codman-Johnson \& Johnson: consulting, significant conflict $(\$ 10,000)$; MicroVention Terumo: consulting, significant conflict $(\$ 10,000)$, Patents (planned, pending, or issued). ReVasc Inc (acquired by Micrus/Codman Neurovascular), Royalties: ReVasc Inc (acquired by Micrus/Codman Neurovascular), Comments: significant conflict $(\$ 10,000)$, Payment for Development of Educational Presentations: Codman Neurovascular. Thomas R. Marotta-RELATED: Consulting Fee or Honorarium: proctoring for PED from ev3, Covidien, Comments: teaching other physicians how to use the device, UNRELATED: Consultancy. Evasc Medical Systems (Vancouver, British Columbia), Comments: some travel expenses, Patents (planned, pending, or issued): patent owner for eCLIPS endovascular flow diverter device. * Money paid to the institution.

\section{References}

1. Szikora I, Berentei Z, Kulcsar Z, et al. Treatment of intracranial aneurysms by functional reconstruction of the parent artery: the Budapest experience with the Pipeline embolization device. AJNR Am J Neuroradiol 2010;31:1139-47

2. Fiorella D, Woo HH, Albuquerque FC, et al. Definitive reconstruction of circumferential, fusiform intracranial aneurysms with the Pipeline embolization device. Neurosurgery 2008;62:1115-20, discussion 1120-21

3. Fiorella D, Kelly ME, Albuquerque FC, et al. Curative reconstruction of a giant midbasilar trunk aneurysm with the Pipeline embolization device. Neurosurgery 2009;64:212-17, discussion 217

4. Lylyk P, Miranda C, Ceratto R, et al. Curative endovascular reconstruction of cerebral aneurysms with the Pipeline embolization device: the Buenos Aires experience. Neurosurgery 2009;64:632-42, discussion 642-43, quiz N636

5. D'Urso PI, Lanzino G, Cloft $\mathrm{HJ}$, et al. Flow diversion for intracranial aneurysms: a review. Stroke 2011;42:2363-68

6. Fiorella D, Hsu D, Woo HH, et al. Very late thrombosis of a Pipeline embolization device construct: case report. Neurosurgery 2010;67(3 suppl operative): E313-14, discussion E314

7. Kulcsar Z, Berentei Z, Marosfoi M, et al. Thromboembolic complication induced stable occlusion of a ruptured basilar tip aneurysm: case report and review of the literature. Interv Neuroradiol 2010;16:83-88

8. Turowski B, Macht S, Kulcsar Z, et al. Early fatal hemorrhage after endovascular cerebral aneurysm treatment with a flow diverter (SILK-Stent): do we need to rethink our concepts? Neuroradiology 2011;53:37-41

9. Kulcsar Z. Rupture of previously unruptured aneurysms after flow diversion treatment. In: Proceedings of the Anatomy-Biology-Clinical Correlations/ Working Group in Interventional Neuroradiology Conference, Val d'Isere, France. January $10-15,2010$

10. Kulcsar Z, Houdart E, Bonafe A, et al. Intra-aneurysmal thrombosis as a pos- 
sible cause of delayed aneurysm rupture after flow-diversion treatment. AJNR Am J Neuroradiol 2010;32:20-25

11. Cebral JR, Mut F, Raschi M, et al. Aneurysm rupture following treatment with flow-diverting stents: computational hemodynamics analysis of treatment. AJNR Am J Neuroradiol 2010;32:27-33

12. Klisch J, Turk A, Turner R, et al. Very late thrombosis of flow-diverting constructs after the treatment of large fusiform posterior circulation aneurysms. AJNR Am J Neuroradiol 2011;32:627-32

13. Serebruany VL, Malinin AI, Ferguson JJ, et al. Bleeding risks of combination vs. single antiplatelet therapy: a meta-analysis of 18 randomized trials comprising 129,314 patients. Fundam Clin Pharmacol 2008;22:315-21

14. Diener HC, Bogousslavsky J, Brass LM, et al. Aspirin and clopidogrel compared with clopidogrel alone after recent ischaemic stroke or transient ischaemic attack in high-risk patients (MATCH): randomised, double-blind, placebocontrolled trial. Lancet 2004;364:331-37

15. Shapiro M, Becske T, Sahlein D, et al. Stent-supported aneurysm coiling: a literature survey of treatment and follow-up. AJNR AM J Neuroradiol 2012; 33:159-63

16. Fiorella D, Albuquerque FC, Woo H, et al. Neuroform stent assisted aneurysm treatment: evolving treatment strategies, complications and results of long term follow-up. J Neurointerv Surg 2010;2:16-22

17. Hampton T, Walsh D, Tolias C, et al. Mural destabilization after aneurysm treatment with a flow-diverting device: a report of two cases. J Neurointerv Surg 2011;3:167-71

18. King JT, Berlin JA, Flamm ES. Morbidity and mortality from elective surgery for asymptomatic, unruptured, intracranial aneurysms: a meta-analysis. J Neurosurg 1994;81:837-42

19. Lessne ML, Shah P, Alexander MJ, et al. Thromboembolic complications after Neuroform stent-assisted treatment of cerebral aneurysms: the Duke Cerebrovascular Center experience in 235 patients with 274 stents. Neurosurgery 2011;69:369-75

20. Naggara ON, White PM, Guilbert F, et al. Endovascular treatment of intracranial unruptured aneurysms: systematic review and meta-analysis of the literature on safety and efficacy. Radiology 2010;256:887-97

21. Orz YI, Hongo K, Tanaka Y, et al. Risks of surgery for patients with unruptured intracranial aneurysms. Surg Neurol 2000;53:21-27, discussion 27-29

22. Shapiro M, Babb J, Becske T, et al. Safety and efficacy of adjunctive balloon remodeling during endovascular treatment of intracranial aneurysms: a literature review. AJNR Am J Neuroradiol 2008;29:1777-81

23. Fischer S, Vajda Z, Aguilar Perez M, et al. Pipeline embolization device (PED) for neurovascular reconstruction: initial experience in the treatment of 101 intracranial aneurysms and dissections. Neuroradiology 2012;54:369-82
24. Brooks NP, Turk AS, Niemann DB, et al. Frequency of thromboembolic events associated with endovascular aneurysm treatment: retrospective case series. J Neurosurg 2008;108:1095-100

25. Grunwald IQ, Papanagiotou P, Politi M, et al. Endovascular treatment of unruptured intracranial aneurysms: occurrence of thromboembolic events. Neurosurgery 2006;58:612-18, discussion 612-18

26. Rordorf G, Bellon RJ, Budzik RE, et al. Silent thromboembolic events associated with the treatment of unruptured cerebral aneurysms by use of Guglielmi detachable coils: prospective study applying diffusion-weighted imaging. AJNR Am J Neuroradiol 2001;22:5-10

27. Soeda A, Sakai N, Sakai H, et al. Thromboembolic events associated with Guglielmi detachable coil embolization of asymptomatic cerebral aneurysms: evaluation of 66 consecutive cases with use of diffusion-weighted MR imaging. AJNR Am J Neuroradiol 2003;24:127-32

28. Safar ME, Blacher J, Mourad JJ, et al. Stiffness of carotid artery wall materia and blood pressure in humans: application to antihypertensive therapy and stroke prevention. Stroke 2000;31:782-90

29. Dobson G, Flewitt J, Tyberg JV, et al. Endografting of the descending thoracic aorta increases ascending aortic input impedance and attenuates pressure transmission in dogs. Eur J Vasc Endovasc Surg 2006;32:129-35

30. Velat GJ, Fargen KM, Lawson MF, et al. Delayed intraparenchymal hemor rhage following Pipeline embolization device treatment for a giant recanalized ophthalmic aneurysm. J Neurointerv Surg 2011 Sep 27. [Epub ahead of print]

31. Vayssettes-Courchay C, Ragonnet C, Isabelle M, et al. Aortic stiffness in vivo in hypertensive rat via echo-tracking: analysis of the pulsatile distension waveform. Am J Physiol Heart Circ Physiol 2011;301:H382-90

32. Sun C, Standish B, Yang VX. Optical coherence elastography: current status and future applications. J Biomed Opt 2011;16:043001

33. Taylor CA, Steinman DA. Image-based modeling of blood flow and vesse wall dynamics: applications, methods and future directions-Sixth International Bio-Fluid Mechanics Symposium and Workshop, March 28-30, 2008 Pasadena, California. Ann Biomed Eng 2010;38:1188-203

34. Price MJ, Berger PB, Teirstein PS, et al. Standard- vs high-dose clopidogrel based on platelet function testing after percutaneous coronary intervention: the GRAVITAS randomized trial. JAMA 2011;305:1097-105

35. Comin J, Kallmes D. Clopidogrel (Plavix). AJNR Am J Neuroradio 2011;32:2002-04

36. Brar SS, ten Berg J, Marcucci R, et al. Impact of platelet reactivity on clinical outcomes after percutaneous coronary intervention: a collaborative metaanalysis of individual participant data. J Am Coll Cardiol 2011; 58:1945-54 